\title{
Venereal disease education and a selected group of American college students
}

\author{
WILLIAM L. YARBER \\ From the Health Education Section, Purdue University, West Lafayette, Indiana, USA
}

SUMMARY Education is considered to be an important factor in the control and possible eradication of venereal diseases. A study was undertaken to discover what effect education had had on a selected group of university students so as to determine suitable avenues for future educational programmes. Many of the schools attended by the students had issued information on venereal diseases; most students considered that this information was useful. The study did not generally show a significant relationship between previous health education, current attitude and behaviour, and the contraction of venereal disease. However, the data did appear to reveal a correlation between the lack of education at junior high school and the acquisition of venereal disease. The university student health service, together with books and pamphlets made available outside the school or classroom, were regarded as being important in venereal disease education. These findings can help those planning venereal disease education for young adults.

\section{Introduction}

Venereal diseases remain a major social health problem in the United States of America.* Consequently, medical personnel and public health officials are continuing to initiate programmes and direct measures towards controlling the diseases.

Among the several accepted solutions to the venereal disease dilemma, education is still a main factor in any overall programme of venereal disease eradication (American Social Health Association, 1973; Bender, 1975). Furthermore, education should mainly be directed towards the most sexually-active groups, particularly young adults (American Social Health Association, 1974). Approximately $67 \%$ of the reported cases of gonorrhoea and $44 \%$ of the reported cases of primary and secondary syphilis in 1973 occurred in the 15-24-year age range (American Social Health Association, 1975).

\footnotetext{
*The American Social Health Association, in its latest report (Today's VD Control Problem, 1975), stated that gonorrhoea continued to increase during the fiscal year 1974 and reached a total of 874161 reported cases, more than double that of six years ago. For the first time since 1969, reported cases of primary and secondary syphilis decreased. The 24728 cases reported in 1974 represent a decrease of 352 cases from 1973. The Association noted, however, that they believe the rate of infectious syphilis is relatively stationary rather than declining.
}

Address for reprints: William L. Yarber, Assistant Professor of Health Education, Lambert Building, Purdue University, West Lafayette, Indiana 47907, USA

Received for publication 9 January 1976
If a significant emphasis is to be placed on education, there must be studies to assess its effect and research into ways of improving it. Studies-for example, those by Manser (1968), Neser and Wiechmann (1967), Rosenblatt and Kabasakalian (1967), Torribio and Glass (1965), Yacenda (1974), Yarber and Williams (1975), and Yarber (1974)have provided pertinent data for improving venereal disease education. Data on previous venereal disease education and present educational needs for a particular population can be a useful guide on the impact of such education and lead to better planning of future instruction.

\section{The problem}

This pilot study was designed to investigate selected aspects of previous venereal disease education, and to determine possible avenues for future education. More specifically, the study was designed to find out:

1. The primary source from which the students had received information on venereal diseases.

2. What venereal disease education they had received at school.

3. What facilities and media they would use to find out about venereal diseases.

A further major aspect of the study was to discover if any relationship existed between these questions and selected characteristics of the population. 
The purpose of this investigation was to provide relevant data for medical personnel and health educators to help them to plan venereal disease education for young adults. The study was a development from a previous research project comprising female students only (Yarber, 1974), and it also included data from a related study by Yacenda (1974).

SOURCE OF DATA

The population of the investigation comprised $373^{*}$ single (and never married) undergraduates from two large, state-supported universities in the central part of the United States of America. The subjects were taken from family life and health education classes and represented a general cross-section of the universities' undergraduate populations. A further description of the population is presented later in this report.

\section{DATA COLLECTION AND TREATMENT}

The data were gathered by the use of a multiplechoice questionnaire specifically designed for the study. This questionnaire was evaluated and revised after being tested on a similar population.

The data were collected during the spring term of 1974-75. The answers were recorded on a computer answer sheet and were given voluntarily and anonymously. The answers given by 68 students who participated in the study were not used because the students were either married (or had been married), or had failed to complete several sections of the questionnaire.

The frequency and percentage of students who chose each question response resulted from the data analysis. Furthermore, the $\chi^{2}$ test, conducted at the 0.05 alpha level, was used to check for a possible relationship between variables of interest.

Interpretations of the findings should take account of the limitations of the data collection procedure and of the questionnaire used.

\section{DESCRIPTION OF THE POPULATION}

A description of the population by sex, age, university class, sexual history, previous venereal disease infection, and size of home town is presented in Table 1.

As shown in Table 1, about two-thirds of the population (238 students) were female and approximately $80 \%$ \% of them were between 19 and 21 years old. Each of the four undergraduate classes was represented by no fewer than 53 students $(14.4 \%)$,

*The total for some variables reported in this study may not be 373 as some subjects failed to answer all the questions.

tThe percentages reported throughout the study are the percentages of the population who responded to the particular question.
Table 1 Characteristics of the study population

\begin{tabular}{|c|c|c|}
\hline Variable & Frequency & $\%$ \\
\hline $\begin{array}{l}\text { Sex }(N=373): \\
\text { Female } \\
\text { Male }\end{array}$ & $\begin{array}{l}238 \\
135\end{array}$ & $\begin{array}{l}63 \cdot 8 \\
36 \cdot 2\end{array}$ \\
\hline $\begin{array}{l}\text { Age }(N=371): \\
18 \text { or younger } \\
19 \\
20 \\
21 \\
22 \\
23 \text { or older }\end{array}$ & $\begin{array}{r}28 \\
91 \\
105 \\
98 \\
36 \\
13\end{array}$ & $\begin{array}{r}7 \cdot 6 \\
24 \cdot 5 \\
28 \cdot 3 \\
26 \cdot 4 \\
9 \cdot 7 \\
3 \cdot 6\end{array}$ \\
\hline $\begin{array}{l}\text { Class }(\mathbf{N}=368): \\
\text { First year } \\
\text { Second year } \\
\text { Junior } \\
\text { Senior }\end{array}$ & $\begin{array}{r}53 \\
133 \\
97 \\
85\end{array}$ & $\begin{array}{l}14 \cdot 4 \\
36 \cdot 1 \\
26 \cdot 4 \\
23 \cdot 1\end{array}$ \\
\hline $\begin{array}{l}\text { Sexual intercourse: } \\
\text { Have participated in intercourse }(N=367) \\
\text { Currently involved in a relationship that } \\
\text { includes intercourse }(N=369)\end{array}$ & 232 & $48 \cdot 7$ \\
\hline $\begin{array}{l}\text { Venereal disease }(\mathbf{N}=365) \text { : } \\
\text { Have contracted a venereal disease }\end{array}$ & 31 & $8 \cdot 5$ \\
\hline $\begin{array}{l}\text { Home town size }(\mathrm{N}=368): \\
\text { Rural under } 2500 \text { population } \\
\text { Urban } 2500-5000 \\
\text { Urban } 5000-10000 \\
\text { Urban } 10000-25000 \\
\text { Urban } 25000-50000 \\
\text { Urban } 50000-100000 \\
\text { Urban } 100000-250000 \\
\text { Urban } 250000-500000 \\
\text { Urban } 500000-1000000 \\
\text { Urban } 1000000 \text { or more }\end{array}$ & $\begin{array}{l}81 \\
11 \\
41 \\
66 \\
50 \\
31 \\
34 \\
21 \\
21 \\
12\end{array}$ & $\begin{array}{r}22 \cdot 0 \\
3 \cdot 0 \\
11 \cdot 1 \\
17 \cdot 9 \\
13 \cdot 6 \\
8 \cdot 4 \\
9 \cdot 2 \\
5 \cdot 7 \\
5 \cdot 7 \\
3 \cdot 3\end{array}$ \\
\hline
\end{tabular}

but most of the students ( 133 or $36.1 \%$ ) were in their second year.

Almost two-thirds of the students (232) reported that they had participated in sexual intercourse and nearly half of them (180) indicated that they were currently involved in a relationship that included sexual intercourse. Thirty-one students $(8.5 \%)$ had contracted a venereal disease.

Home towns were divided into 10 categories according to their size ranging from rural (under 2500 population) to urban (one million population or more) and students were fairly evenly distributed among them.

Students were asked to indicate their current or planned major field of study. Each of the various fields of study (for example, agriculture, business, education, engineering, humanities, preprofessional, sciences, etc.) was represented.

\section{Findings and discussion}

PRIMARY SOURCE OF VD INFORMATION

The main source from which students had received information on venereal diseases is shown in Table 2 . Unlike many areas related to human sexuality in which typically the major source of information is derived from peers and not from school, the data 
reveal that the school was the main source (197 students or $54.7 \%$ ); friends were a minor source (only 32 students or $8.9 \%$ ).

Table 2 Primary source from which students received venereal disease information $(N=360)^{*}$

\begin{tabular}{lcr}
\hline Source & Frequency & $\%$ \\
\hline School & 197 & $54 \cdot 7$ \\
Friends & 19 & $5 \cdot 3$ \\
Parents & 3 & $0 \cdot 8$ \\
Books and pamphlets not in school & 104 & $28 \cdot 9$ \\
Medical doctor & 5 & $1 \cdot 3$ \\
Nurse & 1 & $0 \cdot 2$ \\
Preacher & 0 & $0 \cdot 0$ \\
Boyfriend/girlfriend & 13 & $3 \cdot 6$ \\
Television or radio & 8 & $2 \cdot 2$ \\
Other & 10 & $2 \cdot 7$ \\
\hline
\end{tabular}

*Exact wording of question: 'Where (from what source) have you learned the most about VD? (Choose only one answer).'

The finding that only three students $(0.8 \%)$ received their main source of information from parents reveals that even though education about aspects of sexuality are considered by some as the prerogative of the home, parents played a minor role in informing the students about venereal disease. Possibly venereal disease is too sensitive a topic to be discussed by parents.

Table 2 also shows that many students received their major source of venereal disease information from sources that are considered reliable-that is, about $55 \%$ from school and $29 \%$ from pamphlets and books.

The $\chi^{2}$ test showed no significant relationship between primary source of venereal disease information and the variables: home town size, and ever contracted a venereal disease.

\section{VD EDUCATION IN SCHOOL}

Details of venereal disease education received when at school are presented in Table 3. Approximately $43 \%, 70 \%$, and $64 \%$ indicated that they had received such information at junior high school, senior high school, and in a college class, respectively.

The $\chi^{2}$ test was used to determine if there was any relationship between venereal disease education received when at school and the variables: home town size, ever contracted a venereal disease, ever had intercourse, no sex because afraid of contracting a venereal disease, used venereal disease preventive measures during a sexual experience, would use a condom during intercourse, knowledge of selected venereal disease concepts, and would talk about venereal disease with my sex partner. A significant correlation was established in only one instance, that of venereal disease education at junior high school compared with having contracted a venereal disease $\left(\chi_{4}^{2}=17.23, \quad P=<0.0017\right)$. The $\chi^{2}$ test revealed
Table 3 Previous venereal disease education at school

\begin{tabular}{lcc}
\hline Educational level & Frequency & $\%$ \\
\hline Junior high school (N = 366): & & \\
Was given VD information & 159 & $43 \cdot 4$ \\
Was NOT given VD information & 160 & $43 \cdot 7$ \\
I do not remember & 47 & $12 \cdot 8$ \\
& & \\
Senior high school (N = 370): & 259 & $70 \cdot 0$ \\
Was given VD information & 75 & $20 \cdot 2$ \\
Was NOT given VD information & 39 & $10 \cdot 5$ \\
I do not remember & & \\
& 238 & $64 \cdot 3$ \\
College (N = 370): & 132 & $35 \cdot 7$ \\
Received VD information in a class & \\
Did NOT receive VD information in a class & &
\end{tabular}

that there was a tendency for students who did not learn about venereal diseases at junior high school to indicate more frequently that they had contracted a venereal disease than students who did receive such information. The importance of venereal disease education at junior high school, as expressed by leaders in the field (Bender, 1975; Blanzaco, 1970; Bennell, 1965) and in a statement by the National Commission on Venereal Disease (American Social Health Association, 1973), is supported by this finding.

The absence of a significant relationship between previous venereal disease education at junior and senior high school levels and home town size indicates that the topic, often considered among the sensitive areas of the curriculum, was presented in schools in the rural areas (frequently labelled as more conservative than those in urban localities) as well as at schools in the metropolitan areas. (It is recommended that venereal disease education be included within the communicable disease unit of the health education course and not as a part of a potentially controversial sex education course/unit.)

A $\chi^{2}$ finding that is of particular interest is the comparison of venereal disease education at all three levels and venereal disease infection: the $\chi^{2}$ test showed no significant relationship between having received venereal disease information at the junior high school, senior high school and college levels, and having contracted a venereal disease. This finding seems to refute the suggestion that education repeated at more than one educational level results in more positive health behaviour than education presented at only one level.

Students who had learnt about venereal diseases at any of the educational levels were asked to indicate how helpful the information had been to them and if they had been told about personal protection for a sexually-active person against venereal disease. Overall, these students considered the venereal disease education to be of some value to them as nearly $44 \%$ noted the information as very helpful, 
Table 4 Facilities and media from which students would have sought VD information during previous month $(N=373)$

\begin{tabular}{|c|c|c|c|c|c|}
\hline Facilities* & Frequency & $\%$ & Media $\dagger$ & Frequency & $\%$ \\
\hline University library & 96 & $25 \cdot 7$ & Television & 135 & $36 \cdot 2$ \\
\hline Residence hall counsellor & 8 & $2 \cdot 1$ & Radio & 61 & $16 \cdot 4$ \\
\hline Student health service & 196 & $52 \cdot 5$ & School newspaper & 93 & $24 \cdot 9$ \\
\hline Union building & 21 & $5 \cdot 6$ & City newspaper & 52 & 13.9 \\
\hline Dean of students office & 6 & $1 \cdot 6$ & Magazines, such as Today's Health, & & \\
\hline Guidance and counselling centre & 13 & $3 \cdot 5$ & Psychology Today, etc. & 172 & $46 \cdot 1$ \\
\hline Health education department of university & 44 & $11 \cdot 8$ & Magazine, such as Time, Newsweek, etc. & 105 & $28 \cdot 2$ \\
\hline Planned parenthood & 97 & $26 \cdot 0$ & Magazines, such as Ladies' Home Journal, & & \\
\hline VD clinic & 147 & $39 \cdot 4$ & Readers Digest, etc. & 77 & $20 \cdot 6$ \\
\hline Coffee house & 13 & $3 \cdot 5$ & None & 50 & $13 \cdot 4$ \\
\hline Other & 38 & $10 \cdot 2$ & & & \\
\hline None & 43 & $11 \cdot 5$ & & & \\
\hline
\end{tabular}

*Exact wording of question: 'If VD information had been available from any of the following in the past month, from which ones of these would you have sought VD information? (You may choose more than one answer.)'

tExact wording of question: 'If VD information had been available to you in the past month from the following, which ones would you most likely have used to learn about VD? (You may choose more than one answer.)'

about $50 \%$ rated it a little helpful, and only about $6 \%$ indicated that it was not helpful. Nearly twothirds of the students who had learnt about venereal diseases indicated that they had been given information on prevention.

\section{FACILITIES AND MEDIA}

The facilities and media that would be used to learn about venereal diseases are presented in Table 4 . This information was acquired by asking students to name which facilities and media they would have used during the previous month (assuming information was available from all the listed educational avenues) to learn about venereal diseases.

As indicated in the table, the facility chosen most often was the university student health service; approximately one-half of the population $(52.5 \%$ or 196 students) noted that they would have sought venereal disease information from this source. The next most frequently chosen facility was the university library; but this was chosen by only about half the number of students $(25.7 \%)$ who chose the student health service. The medium indicated most often was the category,Magazines-such as, Today's Health, Psychology Today-chosen by about $46 \%$ (172 students).

An indication of student desire to learn more about venereal disease is revealed by the finding that only about $11 \%$ and $13 \%$ stated that they would not have used a facility and a type of media, respectively, to acquire venereal disease information during the previous month.

\section{Conclusion}

These findings suggest educational strategies and concepts that can be used for improving venereal disease education.

The research indicated that most of the schools in the study have assumed the role of educating about venereal disease and that this education is accepted within the home town communities of the students. However, despite the fact that most students indicated their previous venereal disease education to be of some value to them and that they had received information on preventing contraction, the data, in most instances, did not show a significant relationship between education and selected behaviour and attitudes related to venereal disease, knowledge of selected venereal disease concepts, and the contraction of venereal disease. Since the project dealt only with whether there had been previous education, and was not designed to determine the nature and quality of the education, it is difficult to suggest reasons for the above findings. Nevertheless, the study did reveal a significant relationship between lack of venereal disease education at the junior high school level and the contraction of venereal disease. This finding implies that major educational efforts should be centred on the young adolescent.

The desirability of using books and pamphlets in a non-school setting was suggested in the research. Such material should be made easily available to young adults in places which these persons visit or seek venereal disease information (the university student health service, VD clinic, planned parenthood office, and campus library were the locations most frequently indicated).

The importance of student health service for educating college students about venereal disease was shown in the study. Apparently the students represented in this investigation accept the student health service and feel comfortable visiting it. The study suggests that the student health service can serve as a major source for health information: present programmes should be examined to determine if this role is being met. 
This paper described an investigation designed to provide data for medical personnel and health educators who are involved in education on the venereal diseases. Even though the findings should not be construed as representative of college students as a whole, the data can be useful to those planning venereal disease education for young adults.

\section{References}

American Social Health Association (1973). Today's VD Control Problem 1973, p. 18 and p. 59. The Association: New York.

American Social Health Association (1974). Today's VD Control Problem 1974, p. 10. The Association: New York.

American Social Health Association (1975). Today's VD Control Problem 1975, p. 17. The Association: New York.

Bender, S. J. (1975). Venereal Disease, p. 78 and p. 79. Brown: Iowa.
Bennell, F. (1965). The role of the schools in venereal disease control. Journal of School Health, 35, 258-264.

Blanzaco, A. (1970). VD: Facts You Should Know (Teacher's Manual). Scott, Foresman: Illinois.

Manser, H. (1968). Is education the answer to the venereal disease problem? Journal of the American Osteopathic Association, 67, 1031-1037.

Neser, W. B., and Wiechmann, G. H. (1967). Attitudes of prospective school teachers on teaching venereal disease information. Public Health Reports, 82, 917-920.

Rosenblatt, D., and Kabasakalian, L. (1967). Educating teenagers about venereal disease. Journal of School Health, 37, 432-435.

Torribio, J. A., and Glass, L. H. (1965). Venereal disease exhibit at teenage fair. Public Health Reports, 80, 1-5.

Yacenda, J. A. (1974). Knowledge and attitudes of college students about venereal disease and its prevention. Health Services Reports, 89, 170-176.

Yarber, W. L. (1974). College women and prevention of venereal disease. Journal of the American College Health Association, 22, 412-418.

Yarber, W. L., and Williams, C. E. (1975). Venereal disease prevention and a selected group of college students. Journal of the American Venereal Disease Association, 2, 17-24. 